\title{
COALITION-FORMATION AS A RESULT OF POLICY AND OFFICE MOTIVATIONS IN THE GERMAN FEDERAL STATES
}

\author{
An Empirical Estimate of the Weighting Parameters \\ of Both Motivations
}

Susumu Shikano and Eric Linhart

\begin{abstract}
In this article, we analyze the policy and office motivations of parties in coalition-formation processes at the German federal-state level. We utilize a model developed by Sened that considers both motivations simultaneously and introduces a method by which to estimate its key parameters using data of German state-level coalition-formations.
\end{abstract}

KEY WORDS $\mathbf{n}$ coalition-formation $\mathbf{m}$ Germany $\mathbf{m}$ office motivation $\mathbf{m}$ policy motivation

\section{Introduction}

Theories of coalition-formation can be categorized within two groups: models with office motivations and models with policy motivations. The former assume that only offices motivate parties in the coalition-formation process (e.g. Riker, 1962; Schofield and Laver, 1985). According to the latter, in contrast, coalition-formation depends on the programmatic proximity among parties in the policy space (see Laver and Schofield, 1990, for an overview). Besides these lines of research, there are also models that combine both kinds of motivation. The theory of minimal connected coalitions suggested by Axelrod (1970) is the earliest concept among them. While this model can be seen as a variation of the office-oriented minimal winning coalition, Axelrod reduced the number of predicted coalitions by integrating the connectedness on the unidimensional policy scale. Austen-Smith and Banks (1988), by contrast, introduced a model in which both kinds of motivation are considered equal. A similar model suggested by Crombez (1996) and 
Baron and Diermeier (2001) assumes that a utility function contains both an office-motivated and a policy-motivated part. Sened $(1995,1996)$ extended this model, allowing the weight of these two motivations to vary among parties (see also Schofield and Sened, 2006). His model can be seen as more general, since it includes the purely policy-oriented and purely office-oriented models as special cases. ${ }^{1}$

Despite its theoretical innovation, the application of Sened's model to empirical data has been meagre. While there are some applications in the literature (Giannetti and Sened, 2004; Sened, 1996; Linhart and Shikano, 2007), they remain more akin to a 'stylized case study' rather than systematic quantitative empirical evidence. Most importantly for the purpose of this article is that, to date, there are no systematic quantitative estimates of the weights that parties put on these two complementary motivations. Therefore, one of the goals of this article is to estimate the parameter for both motivations using empirical data. For this purpose, we need enough cases to allow us to shrink the range of possible parameters. German state-level coalition-formations provide an optimal data basis, since these have similar institutional settings - the actors involved are almost identical and politically relevant. By analyzing the German state-level coalition-formations, we also approach a substantive question, which is the second goal of this article. That is, despite their programmatic proximity, Germany's two largest parties, the Christian Democrats and the Social Democrats, have only infrequently formed grand coalitions. We show that this aversion to the grand coalition can be explained partly by the simultaneous consideration of policy and office motivations.

The remainder of this article proceeds as follows: in the next section, we briefly present Sened's original model, but since this model has assumptions that are unrealistic for Germany and/or inappropriate for empirical estimation of the weighting parameters, the third section modifies some elements of Sened's original model. By the end of the fourth section, we will have introduced our data and operationalization. We present the estimated results in the fifth section and the article ends with some discussions.

\section{Sened's Model}

According to Sened's model, a party $i$ evaluates a coalition $C$ in terms of an office utility $u_{i}^{\text {off }}(C)$ as well as a policy utility $u_{i}^{\text {pol }}(C) \cdot u_{i}^{\text {off }}(C)$ is conceived as a relative share of offices which party $i$ obtains in coalition $C$. To estimate the policy utility, Sened considers the legislative decision processes after coalition-formation. Within the framework of a spatial model, one can identify the position $y_{i}$ provoked by party $i$ in the electoral campaign as well as the expected policy output $x(C)$ of coalition $C$ in a policy space. The policy utility $u_{i}^{\text {pol }}(C)$ corresponds to the negative squared distance between $y_{i}$ and $x(C)$. Furthermore, Sened assumes additive separable utility functions such that the overall utility $u_{i}$ of coalition $C$ for a party $i$, defined as: 


$$
u_{i}(C)=\alpha_{i} u_{i}^{\text {off }}(C)+\beta_{i} u_{i}^{\text {oll }}(C)=\alpha_{i} u_{i}^{\text {off }}(C)-\beta_{i}\left\|x(C)-y_{i}\right\|^{2}
$$

with $\alpha_{i}, \beta_{i} \geq 0 ; \alpha_{i}+\beta_{i}=1$, where $\alpha_{i}$ and $\beta_{i}$ are the party-specific weighting parameters for the office and policy motivations. We can interpret this utility function as the gain in the office utility that compensates for the loss in policy utility caused by distance. Therefore, the overall utility can be positive as well as negative.

The above utility function assumes that a policy output $x(C)$ can be completely determined as a result of bargaining during the coalition-formation process. This appears to be realistic if one considers the existence of coalition agreements in many European countries. Nevertheless, the legislative processes are not free of uncertainty, since not all future political issues are known at the time of coalition-formation. Sened integrates this uncertainty within the model by assuming that some policy outputs are more likely than others. Denoting $O$ as the space of all possible policy outputs, one can postulate a probability function $\pi_{C}$ which attributes the likelihood $\pi_{C}(x)$ to every possible policy output $x \in O$. Assuming risk-neutral actors, the expected utility of $C$ for $i$ is:

$$
u_{i}(C)=\alpha_{i} u_{i}^{o f f}(C)-\beta_{i} \int_{x \in \mathrm{O}}\left(\pi_{C}(x)\left\|x-y_{i}\right\|^{2}\right) d x .
$$

To define $\pi_{C}$ more specifically, Sened uses concepts of legislative decisionmaking, e.g. the uncovered set (Giannetti and Sened, 2004; Sened, 1996; cf. Shepsle and Weingast, 1984), the structural stable core (Sened, 1996; cf. Schofield, 1986) or the political heart (Schofield and Sened, 2006; cf. Schofield, 1993). It is usually assumed that all outputs inside the corresponding solution sets are equally probable, while all outputs outside the solution sets have zero likelihood. Denoting the respective solution set by $L_{C}$ and following this probability function, we can specify the utility function as follows:

$$
u_{i}(C)=\alpha_{i} u_{i}^{\text {off }}(C)-\beta_{i} \int_{x \in L_{C}}\left\|x-y_{i}\right\|^{2} d x /\left\|L_{C}\right\| .
$$

To predict which coalition rational actors would form, two criteria are defined: winning and invulnerability. First, rational actors would prefer to be in the opposition $\left(u_{i}(C)=0\right)$ rather than participate in a coalition which results in a negative utility. Therefore, the necessary condition for all potential government coalitions $C^{*}$ is that all participating parties have a nonnegative utility (the winning criterion): ${ }^{2}$

$$
u_{i}\left(C^{*}\right) \geq 0 \text { for all } i \in C^{*} \text {. }
$$

The sufficient condition for the formed coalition is that it assures the highest utility for all participating parties. Denoting $N$ as the set of all parties and $2^{N} \backslash \varnothing$ the set of all possible coalitions, the sufficient condition, or 'invulnerability criterion', can be formalized as follows: ${ }^{3}$

$$
u_{i}\left(C^{*}\right) \geq u_{i}(C) \text { for all } i \in C^{*} \text { and for all } C \in 2^{N} \backslash \varnothing \text {. }
$$


Note that the winning criterion is automatically fulfilled if a coalition is invulnerable. Invulnerability means that a party $i$ as member of a coalition $C^{*}$ values this coalition at least as highly as each alternative coalition $C$. This holds in particular for coalitions in which $i$ is not a member and which are valued by $i$ as 0 . From this it follows that $u_{i}\left(C^{*}\right)$ is not negative if $C^{*}$ is invulnerable.

\section{Some Adjustments of Sened's Original Model}

For the following analysis, we adjust Sened's original model in terms of office utility, the solution set of the legislative stage, the set of potential coalitions to be investigated and application of the invulnerability criterion.

First, Sened's original model gives leeway to parties in terms of the policy output $u_{i}^{\text {pol }}(C)$ as well as the distribution of offices $u_{i}^{\text {off }}(C)$. While on the one hand this renders the model flexible, it risks including unrealistic outcomes on the other. In Germany, there are some unwritten norms to be considered. Imagine, for example, a coalition between highly office-motivated Liberals and highly policy-motivated Christian Democrats. While - with respect to their utility functions - both parties would perhaps agree to form a coalition in which the Liberals held all offices while the Christian Democrats dictated policy, it would be very difficult for either party to explain to their voters. Furthermore, a unique prediction cannot be guaranteed, since more than one solution can be reached through this kind of modelling. To avoid this, we assume a certain fixed office utility for each party in each coalition. More specifically, we follow Gamson's Law, whereby the offices are distributed proportionally to the participating parties' share of seats (Gamson, 1961):

$$
u_{i}^{\text {off }}(C)=s_{i} / \Sigma_{j \in C} s_{j} \text { for all } i \in C,
$$

where $s_{i}$ denotes party $i$ 's share of seats.

This accommodates the fact that Gamson's Law holds almost perfectly in Germany (see Linhart et al., 2008) as well as in other West European democracies (e.g. Browne and Franklin, 1973; Warwick and Druckman, 2006). The proportional distribution of offices seems to be an accepted norm; deviations are only possible within a very small margin. ${ }^{4}$ Note that, by introducing Gamson's Law, we deviate from another important assumption of Sened's original model. While Sened game-theoretically modelled the process in which parties trade policy for office utility and vice versa, our approach is a more decision-theoretical one - that is, decisions under restrictions (Gamson's Law and ideological constellation of parties) are at stake. Therefore, the pure office utility for a party is not endogenous, but assumed to be given on the basis of its share of seats.

Second, Sened's original model and some of its applications thus far assume solution concepts for the legislative process that are independent of the coalition formed. Accordingly, a coalition game has, for example, only one 
political heart, and the anticipated policy output in the following legislative process falls within this set regardless of which coalition has been formed. Regarding this point, Sened does not follow Austen-Smith and Banks' (1988) four-stage model in which the outcome of the coalition-bargaining game influences the legislative game. In Sened's view, coalition 'agreements about policy positions are usually not binding. Therefore, in this model, the results of the election, not the composition of any particular coalition, determine the policy outcome that will be implemented' (1996: 335). Nonetheless, he mentions, depending on the context, that alternative modelling - for example based on the Pareto set - can make sense (Sened, 1996: 335, fn. 5). We are convinced that the Pareto set is more adequate in the German case mainly for two reasons:

(1) There are strong indications that, in Germany, the composition of a coalition government influences the legislative outcome as described by Austen-Smith and Banks' original model. In many cases, the existence of written coalition agreements serve explicitly to regulate the parties, preventing them from overruling each other with the help of opposition parties (the interdiction of changing majorities). Even if those agreements do not exist in written form, they appear to be an accepted political norm by the parties: the outvoting of parties within the government occurs only in very exceptional cases, with most heralding the end of the coalition government.

(2) Sened assumes that the opposition parties' utility equals 0 . This assumption is based on the fact that these parties do not hold any offices $\left(u_{i}^{\text {off }}(C)=0\right)$, but are not made responsible for the policy outcome by the public $\left(u_{i}^{\text {pol }}(C)=0\right)$. Hence, opposition parties should have little or no influence on policy outcomes.

Therefore, the Pareto set is a more appropriate means of modelling the legislative process in Germany. The Pareto set $P_{C}$ of coalition $C$ includes the influence of coalition governments as well as uncertainty (discussed above) in the legislative processes.

Third, while Sened originally did not restrict the potential coalitions for investigation, we take only minimal winning coalitions into account. Surplus majority coalitions and minority governments are excluded from the analysis for the following reasons: each surplus majority coalition is theoretically dominated by all minimal winning coalitions in its subset in terms of office motivation. If any surplus party joins a minimal winning coalition, at least one original coalition partner gains only a reduced number of distributed offices. In terms of policy motivation, the Pareto set of a surplus majority coalition would never be smaller than those of its subset of minimal winning coalitions. Therefore, the sum of policy distance to the possible policy outcomes for all parties is larger in the surplus coalition than in any minimal winning coalitions in its subset. On the contrary, Sened demonstrates the 
possibility that a minority government could be formed. We, however, exclude this possibility for the following two reasons: first, Sened's original model (1996: 361) predicts minority governments only when a central core party dominates the ideologically polarized party system. This has never occurred in the German bipolar system (Laver and Schofield, 1990) except when a single party has won the majority. Second, we assume - by contrast with Sened's original model - that the solution set of the legislative stage depends on the composition of the coalition. If, under this assumption, we allow the formation of minority governments, every party would prefer its single party government because it can then monopolize all offices and the solution set of the legislative state ensuring that it is identical with its policy position. If we apply the invulnerability criterion to this situation, we cannot predict any coalition government but all possible single party governments. This makes no sense and is entirely unrealistic. For the reasons stated above, we consider only minimal winning coalitions as potential governments. The exclusion of minority governments is less problematic, at least in this article, since all German state-level constitutions require the government to have an absolute majority in the formal investiture vote. Empirically, we can find only six minority single party governments and five minority coalitions in our data set out of 111 cases overall.

While the adjustments thus far are more theoretically legitimated, the last one concerning the invulnerability criterion is for a more empirical reason. The invulnerability criterion provides deterministic predictions provided the solution set is not empty. While these kinds of clear predictions are a strength of formal modelling, they could also lead to the so-called 'zero-likelihood problem' (Signorino, 1999: 281; see also Morton, 1999: 116-18) if the predictions have to be tested empirically - in particular, when using a maximum likelihood approach. Within the framework of this standard method of empirical data analysis, likelihood is defined as a product of empirical observations and model predictions expressed in probability as follows:

$$
\mathrm{L}(\theta \mid D)=\Pi p(D \mid \theta),
$$

where $\theta$ is the interested parameter and $D$ is the observed data. Researchers are interested in finding $\theta$ given $D$ is observed. Assume that an interested variable is discrete with the observation vector $z=\left(z_{1}, z_{2}, \ldots, z_{M}\right)$; the likelihood function can be further expressed:

$$
L(\theta \mid z)=\prod_{j} p_{j}(\theta)^{z j},
$$

where $p_{j}(\theta)$ denotes the predicted probability that $j$ is observed. Obviously, the likelihood increases if expected outcomes are frequently predicted with a high probability, and vice versa. Therefore, the set of parameters $\theta$ which maximizes the likelihood is sought. This method, however, only works if all empirically observed outcomes are theoretically predicted with a non-zero 
probability. If at least one outcome is predicted with probability zero (unobserved with certainty), the likelihood is zero for every set of parameters $\theta$, since the likelihood is a product of predicted probability, as shown in the equation above. In this case, the identification of $\theta$ is impossible. And this is often the case for formal models, since predictions of most formal models exclude some possible outcomes which definitely do not lie within their solution set. Thus, the probability is high in that at least one of the observed outcomes in the empirical data is predicted to have a zero probability. If, however, model predictions are not deterministic, but probabilistic, this problem does not arise, because no outcomes are predicted with a probability of zero. For this reason, we apply the invulnerability criterion probabilistically. Further details concerning this are given below. Furthermore, we abandon considering the winning criterion since this is included implicitly when we test for invulnerability.

\section{Data, Operationalization and Estimation Strategy}

As mentioned above in the Introduction, one important goal of this article is to estimate the weighting parameters of both policy and office motivation using empirical data. To this end, we need a certain level of information, or, more concretely, data sets with a certain number of cases. It is not easy to find such data for coalition-formations, however, since only a limited number have generally taken place in individual countries in the past. This problem has at least two solutions: multi-system analysis and sub-system analysis. Martin and Stevenson (2001) exemplify the first solution through putting into the analysis the coalition-formations in as many countries as possible. This produces nothing useful for our purpose, however, since the party systems (the sets of actors) vary across countries, while we attempt to estimate the actor-specific weighting parameters. ${ }^{5}$ The second solution is well exemplified by Bäck (2003), who analyzed coalition-formations at a sub-national level - more specifically for Swedish local governments. This solution is superior to the first in terms of institutional homogeneity and the identical party system (see also Skjæveland et al., 2007). Coalition-formation processes analyzed in this way take place in a relatively homogeneous institutional setting, since the sub-national systems share the same national system. Furthermore, it is likely that the party systems in each sub-system are similar to each other. One caveat of this solution is that analyzed coalition-formations at the sub-national level have to be more or less equivalent to those at the national level (for more details, see, e.g., Bäck, 2003: 35-40).

Being confronted with the case-number problem and two solutions discussed above, we take the second solution using data of German state-level coalition-formations. This approach has some advantages besides the points mentioned above. First, Germany is a federal state in which the states (Bundesländer) are responsible for many important tasks and, additionally, 
exert influence on national-level policy-making via the Federal Council (Bundesrat). State-level coalition-formations are therefore politicized equivalently to those at national level. Second, the political systems of the German states are characterized by parliamentarianism and resemble that of the federal state.

The data analyzed in the following are taken from the coalition-formations between the 1983 and 2005 federal elections. The 1983 election was the first federal election at which the Greens succeeded in entering the national parliament (the Bundestag). Prior to this, the party system at federal level, as well as in most states, had consisted of only three parties in the majority of cases: the Christian Democrats, the Social Democrats and the Liberals. This makes the analysis less interesting, since there are only a very limited number of possible coalitions. Despite the relatively short period of time, there have still been 111 coalition-formations since the 1983 election. However, we are forced to exclude some cases. First, since we are interested in the coalitionformation processes, we excluded 47 coalition-formations in which a single party had an absolute majority. We also had to exclude six further coalitionformations from the analysis since our analysis focused on the explanation of minimal winning coalitions in Germany. Thus, one oversized coalition and five minority governments are not considered here. Two further coalitionformations had to be excluded, since the coalitions actually formed included non-established parties whose policy positions were unknown. As a result, our data set consists of 57 observed coalition-formations.

Our analysis focuses on the five established parties represented in the national parliament: the CDU/CSU (C; the Christian Democrats), the SPD ( $\mathrm{S}$; the Social Democrats), the FDP (F; the Liberals), the Greens $(\mathrm{G})$ and the PDS (P; the Socialists, the former GDR Communists). We assume that the utility of each possible coalition for these five parties determines the coalitionformation processes. To estimate the policy utility $u_{i}^{\text {pol }}(C)$, we have to estimate the policy positions of these parties. One problem, therefore, is that we are modelling the coalition-formation processes among the state-level parties, for which only little information is available. Therefore, we approximate the state-level parties' positions as the estimated ideal points of the corresponding national parties at the precedent national-level election. This assumption is less problematic, at least in the German context. Debus (2008) analyzed the federal- and state-level manifestos and showed overall similarity in the Benelux-type two-dimensional ideological constellation, despite some individual differences. We measure the positions of the national-level parties by using the Comparative Manifesto Project (CMP) data in the following way (cf. Klingemann et al., 2007; Linhart and Shikano, 2007): first, we assume a priori a two-dimensional policy space whose dimensions correspond to the socio-economic and socio-cultural conflict lines. This kind of twodimensional policy space is repeatedly confirmed by multiple empirical studies (see, e.g., Laver and Hunt, 1992). Second, we classify the 56 coding categories of the CMP data into three thematic groups corresponding to the 
two dimensions and a remaining category. Furthermore, we classify the categories into three groups according to their ideological positions: right, neutral and left. Third, we construct the positions for each party on each dimension. The basic idea is similar to the conventional approach, which sums up the relative frequencies of left and right positions and subtracts one from the other (see, e.g., Klingemann et al., 1994). While the conventional approach assumes only one dimension, we implement this separately in the two dimensions defined as a priori. Furthermore, we do not sum up the raw frequencies, but the logarithmized relative frequencies are used to reduce the over-dominating influence of a single category. ${ }^{6}$ Otherwise, the estimated ideological positions would be too sensitive to the frequency of individual categories. More details concerning the construction of party positions appear in the Appendix. Using the party positions constructed in this way, one can construct the Pareto set for each possible coalition. As discussed above, we assume that the likelihood of all possible policy outputs inside a Pareto set is distributed uniformly.

Having measured both components of the utility function, we are now ready to estimate the weighting parameter for them. As mentioned above, we assume a probabilistic decision rule to avoid the zero-likelihood problem. Concretely, this is done by introducing a stochastic term $\varepsilon$ in the utility function:

$$
u_{i}(C)=\gamma_{i}\left[\left(1-\beta_{i}\right) u_{i}^{\text {off }}(C)-\beta_{i} \int_{x \in L_{C}}\left\|x-y_{i}\right\|^{2} d x /\left\|L_{C}\right\|\right]+\varepsilon_{i} .
$$

In favour of estimation economy, $\alpha_{i}$ is here replaced by $1-\beta_{i}$ (cf. the first formula in section 2). $\gamma_{i}$ is an additional party-specific term describing the relative impact of the assumed utility function with respect to an error term $\varepsilon_{i}$. The larger $\gamma_{i}$ is, the smaller the relative impact of $\varepsilon_{i}$ becomes and, therefore, the more important the role of the deterministic component. We can thus interpret $\gamma_{i}$ as the degree of the deterministic decision.

If we further assume that $\varepsilon_{i}$ is distributed according to the Gumbel distribution, the probability that party $i$ decides to join coalition $C^{*}$ is:

$$
\begin{gathered}
\operatorname{Prob}_{i}\left(C^{*}\right)=\exp \left\{\gamma_{i}\left[\left(1-\beta_{i}\right) u_{i}^{\text {off }}\left(C^{*}\right)-\beta_{i} \int_{x \in L_{C}}\left\|x-y_{i}\right\|^{2} d x /\left\|L_{C^{*}}\right\|\right]\right\} / \\
\Sigma_{i \in C} \exp \left\{\gamma_{i}\left[\left(1-\beta_{i}\right) u_{i}^{\text {off }}(C)-\beta_{i} \int_{x \in L_{C}}\left\|x-y_{i}\right\|^{2} d x /\left\|L_{C}\right\|\right]\right\} .
\end{gathered}
$$

Note that this probability concerns the individual decision of parties. If we assume that the individual decision of each party is independent from that of other parties, the likelihood of a coalition is the product of the probabilities of all participating parties within the coalition:

$$
\operatorname{Prob}(C)=\prod_{i \in C} \operatorname{Prob}_{i}(C) .
$$

This probability has to be rescaled, since its sum is unequal to 1 in general:

$$
\operatorname{Prob}(C)=\operatorname{Prob}(C) / \Sigma_{C \in M W C} \operatorname{Prob}(C),
$$

where $M W C$ is a subset of $2^{N} \backslash \varnothing$, that is, the set of all minimal winning coalitions. 
Finally, we can assume that the coalition-formation is based on the multinomial distribution with probabilities $\operatorname{Prob}^{\prime}(C)$.

The estimation of both parameters $\gamma_{i}$ and $\beta_{i}$ is also possible via maximum likelihood. However, it is more appropriate to assume that $\beta_{i}$ is limited between 0 and 1 . Therefore, we search for the beta distribution which fits the parameter estimates for $\beta_{i}$. Furthermore, the beta distribution is highly appropriate for this purpose, since it is quite flexible in its distribution form. $\gamma_{i}$ is assumed to follow the gamma distribution, which takes only nonnegative values and whose shape of distribution is also flexible. Due to these distributional assumptions, the parameters are estimated via a Bayesian approach (Gill, 2002). As prior distribution, a less informative distribution was used for each parameter:

$$
\begin{aligned}
& \beta_{i} \sim B(1,1) \\
& \gamma_{i} \sim \Gamma(3,2) .
\end{aligned}
$$

\section{Results}

\section{Purely Policy-Oriented and Purely Office-Oriented Models}

Before we present the estimated results of the parameters specified above, we make predictions based on the models with only one motivation and observe their empirical validity. This should allow some impressions to be drawn from the data analyzed here.

We begin by observing the predictions of the purely office-oriented model. As discussed above, we assume under Gamson's Law that each participating party receives ministerial posts proportionally to its share of seats. Based on this assumption and the pure office motivation, the prediction based on the invulnerability criterion corresponds to the so-called minimum winning coalition which has the smallest size of seats among the minimal winning coalitions (Gamson, 1961; Riker, 1962). The fourth and fifth columns in Table 1 provide the number of correct and incorrect predictions. Accordingly, the predictions based on the pure office motivation are poor throughout the time period analyzed here. The overall rate of correct predictions is only 28 percent.

To make predictions based on the purely policy-oriented model, we observe the distance from each party to each minimal winning coalition,

$$
\int_{x \in L_{C}}\left\|x-y_{i}\right\|^{2} d x /\left\|L_{C}\right\| .
$$

According to the invulnerability criterion, the predicted coalition is one to which the participating parties have minimal distance on average. ${ }^{7}$ The second and third columns in Table 1 give the number of correctly and incorrectly predicted coalitions. Accordingly, the purely policy-oriented model shows quite a poor predictive performance between 1983 and 1990. At this period of time, no single coalition was correctly predicted. In addition, after 1990, the predictive power of this model remains moderate and the overall 
Table 1. Predictive performance of the purely policy-oriented and office-oriented models

\begin{tabular}{lccccc}
\hline $\begin{array}{l}\text { Federal-level } \\
\text { legislative period }\end{array}$ & \multicolumn{2}{c}{ Purely policy-oriented } & & \multicolumn{2}{c}{ Purely office-oriented } \\
\cline { 2 - 3 } \cline { 5 - 6 } & Correct & Not & & Correct & Not \\
\hline $1983-1987$ & 0 & 5 & & 2 & 3 \\
$1987-1990$ & 0 & 8 & & 5 & 3 \\
$1990-1994$ & 7 & 4 & & 2 & 9 \\
$1994-1998$ & 6 & 6 & & 3 & 9 \\
$1998-2002$ & 5 & 7 & & 3 & 9 \\
$2002-2005$ & 4 & 5 & & 1 & 8 \\
Total & 22 & 35 & & 16 & 41 \\
Correctly predicted & & $39 \%$ & & $28 \%$ \\
\hline
\end{tabular}

rate of the correct predictions is 39 percent. This is higher than that of the purely office-oriented model, but still far from satisfactory. Table 2 gives more information about which coalitions were well predicted. Accordingly, the grand coalition of Christian Democrats and Social Democrats is overpredicted, while the liberal-conservative (CF) and red-green (SG) coalitions are under-predicted. The visual inspection of party positions in fact confirms that the two largest parties, the Christian Democrats and the Social Democrats, are programmatically proximate with each other. Nevertheless, the grand coalition has occurred much less frequently than predicted by proximity. This suggests that one considers not only policy-motivation but also office motivation, since the grand coalition would promise both large parties fewer cabinet posts than the other coalitions.

\section{Estimation of the Model Considering Both Motivations}

Now we observe the estimated results of the model that considers both motivations. We estimate the parameters using two different model specifications. The first simple model sets both parameters as generic for all parties, that is $\alpha_{i}=\alpha_{j}$ and $\beta_{i}=\beta_{j}$ for all observed parties $i, j$. The second model, by contrast, allows both parameters to be variable between parties, i.e. the pair $\left(\alpha_{i} ; \beta_{i}\right)$ is operationalized as dependent on the actor $i$. To observe the posterior distributions of the parameters, 10,000 samples are collected for each model using the Markov-Chain-Monte Carlo method after 10,000 burn-in iterations. Table 3 gives the results for the parameter estimations.

We begin to observe the results of the more restrictive model (model 1) in which both parameters are estimated generically for all parties. The $\gamma$ parameter expresses the impact of the deterministic components of the utility function. Accordingly, a relatively high estimated value for $\gamma$ demonstrates that parties are strongly oriented by the utility consisting of both motivations, and the error term is quite small. The mixture parameter $\beta$ additionally shows 
Table 2. Predicted and actually formed coalitions

\begin{tabular}{llcc}
\hline & $\begin{array}{l}\text { Predicted by the purely } \\
\text { policy-oriented model }\end{array}$ & Actually formed & Difference \\
\hline CS & 33 & 14 & 19 \\
SG & 8 & 13 & -5 \\
SF & 6 & 6 & 0 \\
CF & 5 & 19 & -14 \\
SP & 3 & 3 & 0 \\
SGP & 2 & 0 & 2 \\
SFG & 0 & 2 & -2 \\
Total & 57 & 57 & 0 \\
\hline
\end{tabular}

that the policy motivation outweighs the office motivation (see also Figure 1). Nevertheless, the office motivation is important as an un-ignorable part of the utility, since the rate of correct predictions is 62 percent and much higher than those of the purely office-oriented and policy-oriented models.

If we estimate both parameters specifically for each party, the picture is different. The estimates of $\gamma$ demonstrate that the CDU/CSU is more oriented to the deterministic component of utility, while idiosyncratic factors play an important role in the decisions of the other parties. In terms of the CDU/ CSU's decision-making, the relative weight of the policy motivation $(\beta)$ is quite high. Accordingly, the CDU/CSU should be ready to form the grand coalition when the SPD's position is not far away in the policy space. This suggests that the relatively lower frequency of the grand coalition in the empirical data should be attributed to the other party, the SPD. The estimated results allow us two interpretations: a relatively low level of $\gamma$ implies

Table 3. Estimated results of the model considering both motivations (median and $90 \%$ confidence interval)

\begin{tabular}{llllr}
\hline \multicolumn{4}{c}{ Model 1 } & \multicolumn{3}{l}{ Model 2} \\
\hline$\gamma \quad 8.02(5.87$ & $10.21)$ & & \\
CDU/CSU & & & $9.47(5.61$ & $14.43)$ \\
SPD & & & $2.99(1.57$ & $4.73)$ \\
FDP & & $2.00(0.59$ & $5.07)$ \\
Greens & & $2.64(0.82$ & $5.49)$ \\
PDS & & & $1.21(0.41$ & $2.92)$ \\
$\beta$ & $0.79(0.71$ & $0.88)$ & & \\
CDU/CSU & & & $0.87(0.74$ & $0.98)$ \\
SPD & & & $0.13(0.01$ & $0.44)$ \\
FDP & & & $0.77(0.18$ & $0.99)$ \\
Greens & & $0.72(0.31$ & $0.99)$ \\
PDS & & & $0.42(0.05$ & $0.93)$ \\
Correct predictions (average) & & & $63 \%$ \\
\hline
\end{tabular}




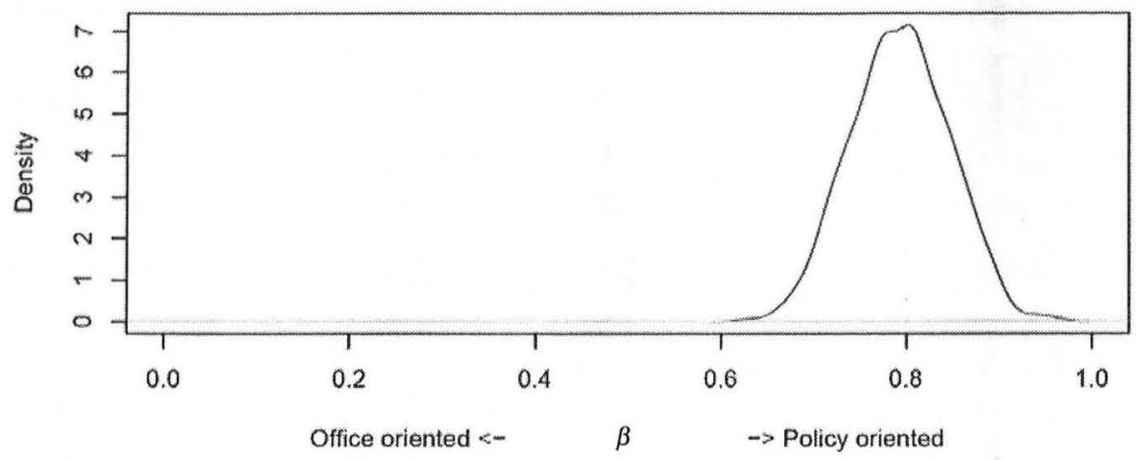

Figure 1. Posterior distribution of $\beta$ (generic for all parties)

that the deterministic component consisting of policy and office motivation plays a less important role in the SPD's decision-making process. Furthermore, the low estimate of $\beta$ shows that the SPD is more interested in office than in policy outputs. These interpretations do not exclude each other and seem to operate simultaneously.

Turning, now, to the estimated results for the smaller parties; the FDP and the Greens tend to be, like the CDU/CSU, more policy-oriented (see Figure 2). Their impact on the decision-making process, however, is less than in that of the CDU/CSU. The most problematic case is the PDS. The low estimate of $\gamma$ demonstrates that the utility function defined by Sened has the least impact among the five parties analyzed here. Furthermore, the relative weight between both motivations is also ambiguous (the lower middle panel of Figure 2). This might be attributed to the long-standing practice after reunification of not viewing the PDS as a possible coalition partner.

While this analysis assumes one party's $\beta$ being common across individual states, one may wonder whether the Bavarian SPD, for example, weighs policy differently from the SPD in Hamburg. Regarding this, Strøm (1990a) argued that a party's weighting between different kinds of motivations depends on organizational and institutional determinants. In terms of organizational factors, German state-level parties have their own relatively independent organizations. However, Germany's strict legal regulation makes organizational features of state-level parties comparable with each other. In terms of institutions, the party systems in the individual federal states are relatively homogeneous. All states adopt proportional representation, possess twodimensional policy spaces and their ministerial structures and competence are comparable with each other. One exception is the extent to which electoral competitiveness varies across the federal states. While the CSU - the Bavarian Christian Democrats - for example, has held a strong position in Bavaria for a long time, races in East German states are often narrow and uncertain. In our view, however, this kind of variation in electoral competitiveness can be offset by the other homogeneous factors across the states. 

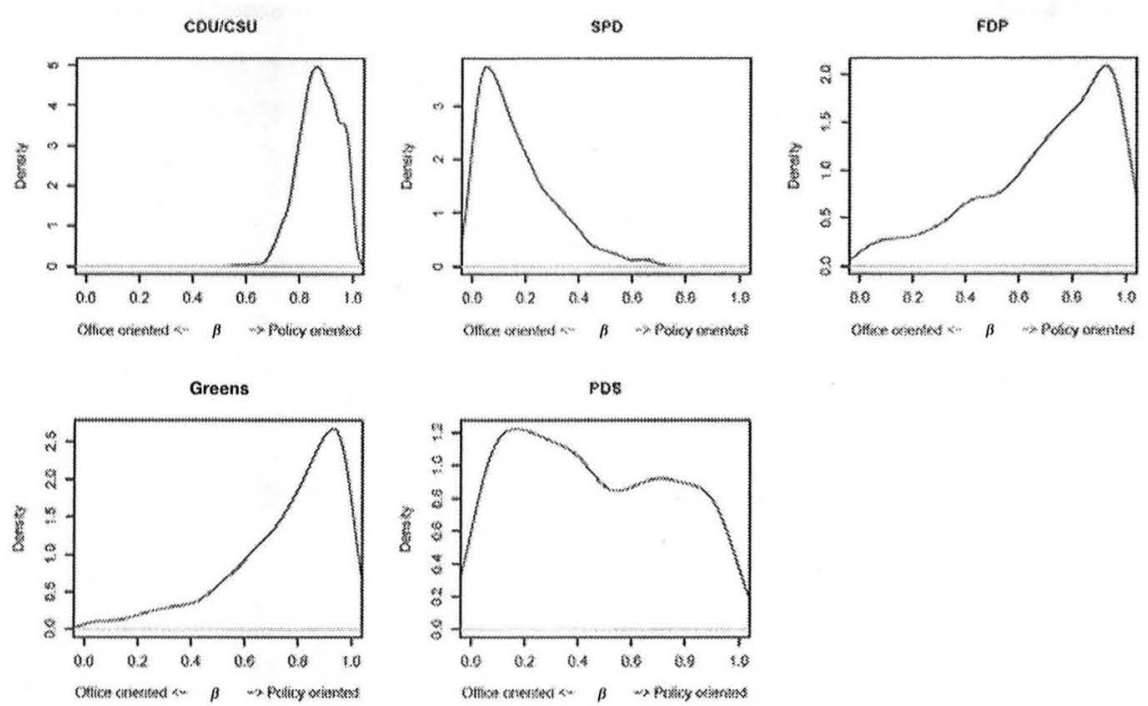

Figure 2. Posterior distribution of $\beta$ (party-specific)

Finally, we have to note that this second model with party-specific parameters improved the rate of correct predictions only marginally compared with that of the first model (63 instaed of 62 percent). ${ }^{8}$ Therefore, we should be cautious in interpreting differences among parties in terms of $\beta$ and $\gamma$. Both models, by contrast, show significantly improved prediction rates compared with those of purely policy-oriented or office-oriented models. We can thus draw the conclusion that both components in the utility function are essential and complementary to each other.

\section{Discussion}

In this article, we have estimated the weighting parameters for both kinds of motivation systematically through using empirical data from German state-level coalition-formations. The results show that it is not sufficient to consider either policy or office motivations of political parties on their own. One can achieve a significant improvement in predictive power by integrating both motivations as separable additive components of a combined utility function. The article shows a systematic way in which this can be done rather than using ad hoc explanations that switch between both kinds of motivation.

This article could be criticized for merely conducting a kind of data fitting, i.e. one assumes an empirical model that consists of multiple theoretical components and looks for the best parameter estimates for each component. For example, Martin and Stevenson (2001), Bäck (2003) and, currently, 
Skjæveland et al. (2007) have already done this kind of research. Furthermore, it is true that these authors also utilized multinomial logit models to estimate parameters, as in this article. The most important difference between this article and the data-fitting approach, however, is that we were not interested in competing theoretical models, but in a single model more systematically developed by Sened. This model is equipped with a welldefined utility function at individual actor level. We have realized the parameter estimation based on the individual random utility model - entirely missed in the data-fitting approach.

Besides the innovation, there are still some tasks for the future that need to be tackled if empirical tests are to be conducted in accordance with Sened's original model. One important caveat of this article was the exclusion of minority governments from the analysis. Our main aim was to take a step towards systematic estimation of weighting parameters. Limiting the set of considered outcomes to minimal winning coalitions is empirically less problematic in the context of German state-level coalition-formations. It is, however, still needed if an estimation strategy is to be realized which can cope with minority governments when we apply our method to further contexts, e.g. in Scandinavian countries (Strøm, 1990b). More importantly, Sened's original model can predict the formation of minority governments. One possible solution would be a further modification in terms of the solution concept for the legislative process. We assumed that minimal winning coalitions can implement policy outcomes in their own Pareto set. By contrast, minority governments can be assumed to implement only policy outcomes in the political heart or uncovered set, since cooperation with opposition parties is necessary (cf. Linhart and Pappi, 2009). This would lower the policy utility of most minority governments and prevent the multiple predictions of all single party governments via the invulnerability criterion.

Another task will be returning to the game-theoretical modelling approach as per Sened's original model. One of the crucial assumptions of model estimation in this article is that individual choices are modelled independently of one another. In this sense, the predictive model here is a decision-theoretical model. One can, however, extend the model by endogenizing the parameters, especially $\beta$. That is, parties can anticipate the decision of their potential coalition partners and, correspondingly, adjust their weighting considering both motivations to maximize their expected utility. This kind of gametheoretical modelling and the analysis of resulting equilibria would serve to further broaden the horizon of this field of research.

\section{Appendix: Constructing Party Positions in the Two-Dimensional Policy Space}

Denote the percentage of category $j$ in the manifesto of party $i$ by $M_{j i}$. We introduce the following two categorizing functions for coding category $j$ : 
$d(j)= \begin{cases}1 & \text { if } j \text { is classified within the socio-economic category. } \\ 2 & \text { if } j \text { is classified within the socio-cultural category. } \\ 3 & \text { if } j \text { is classified within the other categories. }\end{cases}$

$\operatorname{sign}(j)=\left\{\begin{aligned}-1 & \text { if } j \text { is classified as left position. } \\ 0 & \text { if } j \text { is classified as neutral position. } \\ 1 & \text { if } j \text { is classified as right position. }\end{aligned}\right.$

Now, we can estimate the ideal position for party $i$ as follows:

Ideal position on the socio-economic dimension:

$$
y_{i}=\sum_{\substack{j=1 \\ d(j)=1}}^{56} \operatorname{sign}(j) \cdot \ln \left(1+M_{j i}\right) / \sum_{\substack{j=1 \\ d(j)=1}}^{56} \ln \left(1+M_{j i}\right)
$$

Ideal position on the socio-cultural dimension:

$$
y_{i}=\sum_{\substack{j=1 \\ d(j)=2}}^{56} \operatorname{sign}(j) \cdot \ln \left(1+M_{j i}\right) / \sum_{\substack{j=1 \\ d(j)=2}}^{56} \ln \left(1+M_{j i}\right)
$$

Appendix Table. Categorizing functions for the categories in the CMP data

\begin{tabular}{lllc}
\hline Category & $d(j)$ & $\operatorname{sign}(j)$ \\
\hline 104 & Military: Positive & 2 & 1 \\
105 & Military: Negative & 2 & -1 \\
201 & Freedom and Human Rights: Positive & 2 & -1 \\
202 & Democracy: Positive & 2 & -1 \\
401 & Free Enterprise: Positive & 1 & 1 \\
402 & Incentives: Positive & 1 & 1 \\
403 & Market Regulation: Positive & 1 & 0 \\
404 & Economic Planning: Positive & 1 & -1 \\
405 & Corporatism: Positive & 1 & 0 \\
406 & Protectionism: Positive & 1 & -1 \\
407 & Protectionism: Negative & 1 & 1 \\
408 & Economic Goals & 1 & 0 \\
409 & Keynesian Demand Management: Positive & 1 & -1 \\
410 & Productivity: Positive & 1 & 0 \\
411 & Technology and Infrastructure: Positive & 1 & 0 \\
412 & Controlled Economy: Positive & 1 & -1 \\
413 & Nationalization: Positive & 1 & -1 \\
414 & Economic Orthodoxy: Positive & 1 & 1 \\
415 & Marxist Analysis: Positive & 1 & -1 \\
416 & Anti-Growth Economy: Positive & 1 & -1 \\
\hline
\end{tabular}


Appendix Table. Continued

\begin{tabular}{|c|c|c|c|}
\hline \multicolumn{2}{|c|}{ Category } & \multirow{2}{*}{$\frac{d(j)}{2}$} & \multirow{2}{*}{$\frac{\operatorname{sign}(j)}{0}$} \\
\hline 502 & Culture: Positive & & \\
\hline 503 & Social Justice: Positive & 1 & -1 \\
\hline 504 & Welfare State Expansion: Positive & 1 & -1 \\
\hline 505 & Welfare State Limitation: Positive & 1 & 1 \\
\hline 601 & National Way of Life: Positive & 2 & 1 \\
\hline 602 & National Way of Life: Negative & 2 & -1 \\
\hline 603 & Traditional Morality: Positive & 2 & 1 \\
\hline 604 & Traditional Morality: Negative & 2 & -1 \\
\hline 605 & Law and Order: Positive & 2 & 1 \\
\hline 607 & Multiculturalism: Positive & 2 & -1 \\
\hline 608 & Multiculturalism: Negative & 2 & 1 \\
\hline 701 & Labour Groups: Positive & 1 & -1 \\
\hline 702 & Labour Groups: Negative & 1 & 1 \\
\hline 703 & Farmers: Positive & 1 & 0 \\
\hline 704 & Middle-Class and Professional Groups: Positive & 1 & 1 \\
\hline 705 & Underprivileged Minority Groups: Positive & 2 & -1 \\
\hline 706 & Non-Economic Demographic Groups: Positive & 2 & 0 \\
\hline
\end{tabular}

Categories attributed to none of the dimensions are excluded from this table.

\section{Acknowledgement}

We would like to thank Hanna Bäck, Thomas Bräuninger, Marc Debus, Patrick Dumont, Thomas Gschwend, Tasos Kalandrakis, Matthias Lehnert, Johannes Marx, Franz U. Pappi, Lieven De Winter and three anonymous reviewers for their helpful comments on a previous version of this manuscript.

\section{Notes}

1 Another extension is proposed by Kalandrakis (2007), who combines a bargaining model that includes a formateur (Baron and Ferejohn, 1989) with a model, similar to Sened's, using a combined utility function that allows for both policy and office motivation.

2 The winning criterion is redefined by Sened with respect to the utility function applied here. In this context, 'winning' does not mean that a coalition holds more than 50 percent of the seats in a parliament.

3 It is not completely correct to label this criterion as 'sufficient', because more than one coalition can be predicted with it. More precisely, the formation of every coalition fulfilling this criterion is in equilibrium, since no participating party has an incentive to leave the coalition and form another. Our definition holds for the subset of minimal winning coalitions which we research in this article. Regarding the whole set of all possible coalitions, this definition would become more complicated and have to be refined. 
4 Note that we do not necessarily deduce minimum winning coalitions, or coalitions with the smallest size, from Gamson's Law, as Gamson did. It is well known that minimum winning coalitions often fail to predict the coalition actually formed, which also applies to the empirical test below. In contrast, we add the policy component to the office component to make predictions. Correspondingly, we can also predict non-minimum winning coalitions as well.

5 Another drawback of this solution is that it introduces a nearly uncontrollable institutional heterogeneity across countries. Correspondingly, one needs a number of control variables at the cost of sacrificing a greater degree of freedom.

6 More precisely, we add 1 to each relative frequency before it is logarithmized. This is necessary since $\log (0)$ equals negative infinity, which cannot be summed and $\log (1)=0$, such that this addition is necessary to map the zero-point onto itself.

7 Here, we make predictions using the deterministic decision rule, since we do not need to estimate the parameters.

8 These rates are an average of 10,000 prediction rates. As stated above, the posterior distributions of estimated parameters consist of 10,000 samples. This means that there are 10,000 sets of parameter estimates. Correspondingly, we have 10,000 rates of correct predictions.

\section{References}

Austen-Smith, David and Jeffrey Banks (1988) 'Elections, Coalitions, and Legislative Outcomes', American Political Science Review 82: 405-22.

Axelrod, Robert (1970) Conflict of Interest. A Theory of Divergent Goals with Application to Politics. Chicago, IL: Markham.

Bäck, Hanna (2003) Explaining Coalitions: Evidence and Lessons from Studying Coalition Formation in Swedish Local Government. Uppsala: Uppsala University Press.

Baron, David P. and John A. Ferejohn (1989) 'Bargaining in Legislatures', American Political Science Review 83: 1181-206.

Baron, David P. and Daniel Diermeier (2001) 'Elections, Governments, and Parliaments in Proportional Representation Systems', Quarterly Journal of Economics 116: 933-67.

Browne, Eric C. and Mark N. Franklin (1973) 'Aspects of Coalition Payoffs in European Parliamentary Democracies', American Political Science Review 67: 453-69.

Crombez, Christophe (1996) 'Minority Governments, Minimal Winning Coalitions and Surplus Majorities in Parliamentary Systems', European Journal of Political Research 29: 1-29.

Debus, Marc (2008) 'Party Competition and Government Formation in Multilevel Settings: Evidence from Germany', Government and Opposition 43: 505-38.

Gamson, William A. (1961) 'A Theory of Coalition Formation', American Sociological Review 26: 373-82.

Giannetti, Daniela and Itai Sened (2004) 'Party Competition and Coalition Formation: Italy 1994-96', Journal of Theoretical Politics 16: 483-515.

Gill, Jeff (2002) Bayesian Methods: A Social and Behavioral Sciences Approach. Boca Raton, FL: Chapman and Hall. 
Kalandrakis, Tasos (2007) 'A Theory of Minority and Majority Governments'. Mimeo. University of Rochester.

Klingemann, Hans-Dieter, Richard I. Hofferbert and Ian Budge (1994) Parties, Policies and Democracy. Boulder, CO: Westview Press.

Klingemann, Hans-Dieter, Andrea Volkens, Judith Bara, Ian Budge and Michael McDonald (2007) Mapping Policy Preferences II: Estimates for Parties, Electors and Governments in Central and Eastern Europe, European Union and OECD 1990-2003. Oxford: Oxford University Press.

Laver, Michael and W. Ben Hunt (1992) Policy and Party Competition. New York: Routledge.

Laver, Michael and Norman J. Schofield (1990) 'Multiparty Government', Politics of Coalition in Europe. Oxford: Oxford University Press.

Linhart, Eric and Franz U. Pappi (2009) 'Koalitionsbildungen zwischen Ämter-und Politikmotivation. Konstruktion einer interdependenten Nutzenfunktion' (Coalition bargaining between office and policy motivation. The construction of an interdependent utility function), Politische Vierteljahresschrift 50: 23-49.

Linhart, Eric, Franz U. Pappi and Ralf Schmitt (2008) 'Die proportionale Ministeriumsaufteilung in deutschen Koalitionsregierungen: Akzeptierte Norm oder das Ausnutzen strategischer Vorteile?' (The Proportional Distribution of Portfolios in German Coalition Governments: Behavioural Norm or Realization of Competitive Advantages?), Politische Vierteljahresschrift 49: 46-67.

Linhart, Eric and Susumu Shikano (2007) 'Die große Koalition in Österreich: Schwierigkeiten bei der Bildung, Stabilität und Alternativenlosigkeit' (The grand coalition in Austria: Difficulties of formation, stability, and lack of alternatives), Österreichische Zeitschrift für Politikwissenschaft 36: 185-200.

Linhart, Eric and Susumu Shikano (2009) 'Ideological Signals of German Parties in a Multi-Dimensional Space', German Politics (forthcoming).

Martin, Lanny W. and Randolph T. Stevenson (2001) 'Government Formation in Parliamentary Democracy', American Journal of Political Science 45: 33-50.

Morton, Rebecca B. (1999) Methods and Models: A Guide to the Empirical Analysis of Formal Models in Political Science. Cambridge: Cambridge University Press.

Riker, William H. (1962) The Theory of Political Coalitions. New Haven, CT: Yale University Press.

Schofield, Norman J. (1986) 'Existence of a "Structurally Stable" Equilibrium for a Non-Collegial Voting Rule', Public Choice 51: 267-84.

Schofield, Norman J. (1993) 'Party Competition in a Spatial Model of Coalition Formation', in William A. Barnett, Melvin J. Hinich and Norman J. Schofield (eds) Political Economy. Institutions, Competition, and Representation, pp. 135-74. Cambridge: Cambridge University Press.

Schofield, Norman J. and Michael Laver (1985) 'Bargaining Theory and Portfolio Payoffs in European Coalition Governments 1945-83', British Journal of Political Science 15: 143-64.

Schofield, Norman J. and Itai Sened (2006) Multiparty Democracy. Elections and Legislative Politics. Cambridge: Cambridge University Press.

Sened, Itai (1995) 'Equilibria in Weighted Voting Games with Side Payments', Journal of Theoretical Politics 7: 283-300.

Sened, Itai (1996) 'A Model of Coalition Formation: Theory and Evidence', Journal of Politics 58: 350-72. 
Shepsle, Kenneth A. and Barry R. Weingast (1984) 'Uncovered Sets and Sophisticated Voting Outcomes with Implications for Agenda Institutions', American Journal of Political Science 28: 49-74.

Signorino, Curtis S. (1999) 'Strategic Interaction and the Statistical Analysis of International Conflict', American Political Science Review 93: 279-97.

Skjæveland, Asbjørn, Søren Serritzlew and Jens Blom-Hansen (2007) 'Theories of Coalition Formation: An Empirical Test Using Data from Danish Local Government', European Journal of Political Research 46: 721-45.

Strøm, Kaare (1990a) 'A Behavioral Theory of Competitive Political Parties', American Journal of Political Science 34: 565-98.

Strøm, Kaare (1990b) Minority Government and Majority Rule. Cambridge: Cambridge University Press.

Warwick, Paul V. and James N. Druckman (2006) 'The Portfolio Allocation Paradox: An Investigation into the Nature of a Very Strong but Puzzling Relationship', European Journal of Political Research 45: 635-65.

SUSUMU SHIKANO is Professor of Political Methodology at the University of Konstanz, Germany. His publications have appeared in German Politics, Politische Vierteljabresschrift, Public Choice and West European Politics.

ADDRESS: Department of Political Science and Management, University of Konstanz, Postbox 92, D-78457 Konstanz, Germany. [email: susumu.shikano@uni-konstanz.de]

ERIC LINHART is Assistant Professor (Junior Professor) of Applied Political Economy at the University of Kiel, Germany. His main research foci are coalition theory, electoral systems and electoral behaviour, legislative studies and decision theory. ADDRESS: Department of Agricultural Economics, University of Kiel, Olshausenstr. 40, D-24098 Kiel, Germany. [email: eric.linhart@ae.uni-kiel.de] 